\title{
THE PSYCHOLOGICAL CONDITION OF RUSSIAN SOCIETY IN THE CONTEXT OF THE COVID-19 PANDEMIC
}

\author{
Olga Deyneka ${ }^{1}, \&$ Alexandr Maksimenko ${ }^{2}$ \\ ${ }^{1}$ Department of Psychology, Saint-Petersburg State University (Russia) \\ ${ }^{2}$ Laboratory of Anti-Corruption Policy, National Research University "Higher School of Economics» \\ (Russia)
}

\begin{abstract}
The problem of the psychological impact of a pandemic, quarantine and self-isolation on the state of society attracts increased attention of specialists (Hua J., Shaw R., 2020; Li S., Wang Y. et all, 2020, Enikolopov S. et all, 2020; Fedosenko E., 2020). The objective of our work was to find the most common attitudes and types of responses of Russians to the epidemic COVID-19 taking into account their involvement in social networks, critical thinking and severity of psychopathological symptoms. The study was carried out during the recession of the first wave of the pandemic in early June 2020. The main tool was the questionnaire of T. Nestik in an abridged version. Additionally, a questionnaire of critical thinking was used (CTI, Epstein, adapted by S. Enikolopov and S. Lebedev, 2004); test of psychopathological symptoms SCL-90-R; social media engagement questionnaire (Karadag, 2015) was used. The study involved 986 people (56.9\% male, $43.1 \%$ female) aged 18 to 76 years. Using exploratory factor analysis, 6 types of responses to the epidemic situation caused by COVID-19 were identified (fans / opponents of the "conspiracy theory"; responsible / irresponsible, covid-dissidents, covid-optimists, misophobes, anti-vaccinators). The dominant belief among the respondents is that the emergence of new infectious diseases is a natural process of mutation that occurs in nature without the participation of people, or the result of someone's mistake. Conspiracy theories were significantly more common among elderly people and women. Citizens see salvation from the epidemic in the moral conscience and responsibility of everyone. At the same time, they do not trust both official information and information from fellow citizens. Representatives of the older generation have higher confidence in the country's leadership, in the possibilities of medicine and science, and in fellow citizens. Correlations of non-critical thinking with manifestations of misophobia and fear of new epidemics were revealed. Depressive subjects were more concerned about the illegal behavior of fellow citizens and misophobia. Long-term fear of epidemics has been correlated with anxiety. Among those who prefer social networks to official information (television, radio, print), statistically significantly more are those who not only do not trust official information about the epidemic situation, but also do not trust their fellow citizens, attributing to them possible facts of concealing information about the disease because of the fear of being quarantined. Thus, the COVID-consciousness of Russians demonstrated a combination of rather contradictory attitudes.
\end{abstract}

Keywords: COVID-19, attitude towards the pandemic, psychological condition of society, Russian society, typology.

\section{Introduction}

The problem of the psychological impact of a pandemic, quarantine and self-isolation on the state of society attracts increased attention of specialists. The works of scientists from China, Italy, Japan, Spain, France and other countries published since December 2019 analyze the impact of the pandemic on the emotions and behavior of people, the first reaction to challenges and a reformatted way of life during the outbreak of the epidemic (see: Deyneka, Maksimenko, 2020). Negative psychological reactions of people to threats to health, life, well-being and stability in society were intensified by "infodemia". Aggravation of economic and environmental problems was recorded, in particular, a decrease in confidence in the future (Jia at al., 2021), panic buying behavior (Naeem). Some studies have identified not only negative (Liu et al., 2021), but also positive effects of communication on social networks (Mohamad, 2020; Jia at al., 2021) and changes in society. The need for psychological monitoring of the state of society against the background of the epidemiological situation is obvious. 


\section{Background}

The results of empirical studies of the state of Russian society and its adaptation to the pandemic caused by COVID-19 have been covered in scientific and journalistic literature since March 2020. For example, E.V. Fedosenko (2020) results of a study of human psychological resources during the period of forced isolation. The most common reactions of respondents $(\mathrm{N}=784$ people) to the epidemic situation are highlighted. Fear (47.3\%), apathy $(22.2 \%)$, stupor $(14.5 \%)$ formed the three most common responses to forced isolation. Also, such psychological "effects" of epidemics and related quarantines as anger, irritation, depression, emotional exhaustion, symptoms of post-traumatic stress were recorded. The author has characterized the epidemic situation as an emergency due to the "psychological effects" that it provokes.

S. N. Enikolopov and his colleagues (2020), having interviewed 430 people at the end of March 2020 using a battery of questionnaires, obtained evidence of an increase in the number of people who view the pandemic as a result of the use of biological weapons, punishment for sins, and retribution for neglect of environmental problems. The respondents showed a statistically significant increase in depression; sleep worsened; the level of anxiety, fear and panic increased. At the same time, it was noted that Russians turned to religion, the level of constructive thinking and emotional coping fell.

T. A. Nestik (2020) identified 4 types of responses encountered by citizens during an epidemic. The highest level of stress was experienced by "skeptics" (20\%), who had a low level of trust in state authorities and official information and consider the threat of a pandemic to be exaggerated. "Alarmists" (30\%) showed the greatest concern about the pandemic, believing that everything is much worse than it was broadcasted in the official media, and that more stringent regulatory measures should have been taken in society. "Fatalists" (25\%) were convinced that little depends on people and assessed the prospects very pessimistically, developing conspiracy theories on social networks. And finally, "optimists" (25\%) considered the threat to be serious, but showed more inclination to empathize with others, more faith in their own strengths and in the efforts of the state.

The objective of this study was to find the most common attitudes and types of responses of Russians to the epidemic COVID-19 taking into account their involvement in social networks, critical thinking and severity of psychopathological symptoms.

\section{Method}

In this study, data was collected through the Toloka.Yandex.ru service for two weeks (from May 31 to June 10, 2020 with the highest number of responses on June 2 and 9). Since the study was conducted during the recession of the first wave of the COVID-19 pandemic, expectations were associated with the accumulation of some experience in adapting to the epidemiological situation in Russia.

Sample. The study involved 986 people (56.9\% males, $43.1 \%$ females) aged 18 to 76 years $(\mathrm{M}=36.63 ; \mathrm{SD}=10.2)$. The survey geography covered various regions of Russia.

Instruments. The main research tool was a shortcut version of the questionnaire developed by $\mathrm{T}$. Nestik to measure attitudes to the pandemic and assess trust in representatives of various social groups (Nestik, 2020), which included 34 statements with a five-point Likert response scale.

Additionally, the symptomatic method SCL-90-R, the questionnaire of critical thinking (CTI, Epstein, 2001 adapted by Enikolopov and Lebedev, 2004), Social Media Addiction Scale of 10 statements with a 5-point scale were used (The reliability of the questionnaire was confirmed by the Cronbach alpha coefficient 0.864 ). Also, the survey involved filling out a demographic information.

Data processing included exploratory factor analysis with Varimax rotation and Kaiser normalization, and correlation analysis using Spearman's coefficient. The calculation of descriptive statistics, correlation and factor analysis were performed using the statistical package SPSS 20.0.

\section{Results}

Factorization of the data from the pandemic attitudes' questionnaire yielded eight factors, the last four of which are represented by low factor weights, but can be considered in the context of the general diversity of typical attitudes and perceptions that arose in response to the epidemic situation.

The first factor was named "the factor of conspiracy theories about coronavirus." This factor accounts for $15.9 \%$ of the explained variance. It contains the opposition of the idea of the causative agent of a pandemic as a man-made, artificially created by a certain "enemy", as a biological weapon, or, on the contrary, a natural, inartificial phenomenon.

The second factor "covid-dissidence" $(12.0 \%$ of the variance) includes ignoring the danger of infection in combination with a fatalistic approach to the danger (probability) of getting sick. With fewer 
contributions, it included manifestations of a negative attitude towards vaccinations, which confirms the fact that among covid dissidents there are more of those who are called "anti-vaccines".

The third factor "covid-optimism" is formed by trust in the Governance against the backdrop of a pandemic, faith in domestic medicine and world science, and with the opposite sign (with a small factor load), the factor includes hope only for oneself and one's loved ones in case of infection.

The fourth factor "trust and responsibility in society" embodies the awareness of problems related to the responsibility or irresponsibility of members of society against the background of a pandemic and trust / distrust in the systems "citizen-state" and "citizen-society".

The fifth factor, called "fear of infection and misophobia", is formed by the fear of contracting the COVID-19 virus in public places (in transport or at a clinic reception) and refusal to visit them.

Against the background of a pandemic, the manifestations of misophobia (the desire to minimize the need to interact with strangers and avoid touching various things due to the fear of microbes) were provoked by an epidemic situation, i.e., we are talking about situational anxiety and cautious (sometimes excessive) behavior.

Fears, anxiety, panic moods in different forms are embodied in two more factors. Thus, in the sixth factor, or "the factor of fear, repentance and charity," the fear of new epidemiological threats and more dangerous epidemics in the future is combined with the interpretation of the pandemic as punishment for sins and a willingness to donate money to elderly people who fell ill during the epidemic.

The seventh factor "predictive pessimism" embodies doom, apocalyptic sentiments ("it is likely that in the next 50 years there will be an epidemic from which all people will die"), the expectation of new epidemic threats, doubts about the benefits and safety of vaccinations. The eighth factor "preference for strict restrictive measures" united the approval / disapproval of prison sentences for violation of quarantine, the requirement for transparency of movement and contacts of the sick, even to the detriment of privacy, regulation of the life of citizens with iron discipline to save from the epidemic.

Thus, the resulting factorial structure of the survey data reflects the spectrum of rather contradictory attitudes of the Russians' covid consciousness.

As the analysis of descriptive statistics shows, the prevailing belief among respondents is that the emergence of new infectious diseases is a natural process of mutation that occurs in nature without the participation of humans, or the result of someone's mistake. Conspiracy explanations for the emergence of a new infection, called COVID-19, were not popular among Russians in the first ten days of June 2020. The explanation of the pandemic as a punishment of the God turned out to be even less popular $(\mathrm{M}=1.68$, $\mathrm{SD}=1.02$ ).

The greatest degree of agreement among the Russians participating in the survey was received by the statements from the fourth factor, which reflects trust and responsibility in society. Most of the respondents agree with the opinion that the only salvation from the epidemic lies in the moral conscience and responsibility of everyone $(\mathrm{M}=3.95, \mathrm{SD}=1.07)$. At the same time, citizens tend to distrust both official information about the number of infected with covid $(\mathrm{M}=3.68, \mathrm{SD}=1.03)$ and information from fellow citizens who "will conceal the fact of infection with the virus" $(\mathrm{M}=3.52, \mathrm{SD}=1.05)$.

In terms of severity, trust in world science, which will ensure the creation of a cure for an insidious virus, and trust only in oneself and in the inner circle of people in case of illness, turned out to be practically the same. It should be borne in mind that the study was carried out before the development of the Sputnik $\mathrm{V}$ vaccine.

\section{Demographic characteristics of pandemic attitudes}

Despite the statistically significant predominance with age of predictive anxiety about epidemiological threats $(\mathrm{p}<0.01)$ and specifically recurrence of epidemics in the coming years $(\mathrm{p}<0.001)$, as well as fears of side effects of vaccinations $(p<0.01)$, representatives of the older generation showed more confidence in the country's leadership in its efforts to contain the pandemic $(p<0.001)$. Confidence in the capabilities of medicine and science for saving the majority of patients also turned out to be higher with age $(\mathrm{p}<0.01)$.

The data indirectly indicate a higher confidence in the World Health Organization, which manifested itself in less agreement $(p<0.001)$ with measures regulating the information flow ("in order to prevent panic, it is necessary to suppress the spread of news that differs from official information and WHO recommendations").

In addition, the factor of age (which may indicate a greater maturity of the individual) manifested itself in greater confidence in fellow citizens in a pandemic situation. The older the respondents were, the less they showed agreement that "in the event of an epidemic, most people will not report that they are sick, so as not to be quarantined" ( $p<0.001$ ), that "most Russians will not believe the official information on the number of cases and deaths during a pandemic $(p<0.01)$. At the same time, among the older generation, there were more of those who believe that security is more important than the right to privacy (contacts and movements) $(p<0.001)$. 
At the same time, the results of the study showed that the older the respondents were, the more among them were supporters of conspiracy and fatalistic theories of the origin of the pandemic ("viruses like COVID-19 are created artificially for some purpose" $(\mathrm{p}<0.001)$, "Epidemics are God's punishment" $(\mathrm{p}<0.001)$, "with the help of epidemics, the rich regulate the number of the poor" $(\mathrm{p}<0.01))$. Accordingly, fewer were those who believed that the pandemic was caused by chance or a natural process of mutations $(\mathrm{p}<0.01)$.

According to the data obtained, women believe more in conspiracy theories and more often agree that "viruses are created artificially for some purpose" $(\mathrm{p}<0.05)$, as well as that "the outbreak is the result of someone else's mistake" $(\mathrm{p}<0.05)$. There were more skeptics among men who agree that "during epidemics, information on the number of infected people will be deliberately distorted so as not to sow panic" ( $p<0.05$ ) and that "the media hype about COVID-19 is used to distract attention of society from more important problems" $(p<0.05)$. Men more often agreed that "pharmaceutical companies deliberately delay the release of certain drugs so that they will cost more in the future" $(p<0.05)$.

Women are more likely than men to show phobias, significantly more often agreeing that they are more afraid of new more dangerous epidemics $(\mathrm{p}<0.05)$, and also more afraid to use public transport $(p<0.05)$ and come to an appointment at the clinic $(p<0.05)$, for fear of contracting the virus.

\section{Pandemic Attitudes and Psychopathological Trends}

Correlation analysis of the data from the questionnaire of attitudes towards the pandemic and the questionnaire of the severity of psychopathological symptoms SCL-90-R showed that persons with high scores on the anxiety scale have higher fears about new and more dangerous epidemics $(p<0.001)$ and expectations of negative news about epidemiological threats. The higher the indicators on the scale of depression and the scale of phobic anxiety, the higher the manifestations of misophobia $(p<0.001)$, the less trust in people around and the more suspicions about their non-compliance with epidemiological rules $(p<0.001)$. Individuals with high scores on the hostility scale advocate jail sentences for those who violate quarantine $(\mathrm{p}<0.001)$.

\section{Attitudes towards a pandemic and critical thinking}

The average data on the critical thinking questionnaire (CTI) on all scales were located in the normative zone. Against the background of the loosening of the self-isolation regime in early June 2020, the manifestations of categorical and personal-superstitious thinking increased slightly.

Correlation analysis of the data from the pandemic and CTI questionnaire showed that news about epidemiological threats causes less anxiety in persons with high scores on the emotional coping scale $(\mathrm{r}=-0.237, \mathrm{p}<0.001)$ and the general constructive thinking scale (GCTI). The higher the GCTI scores, the lower the adherence to conspiracy theories of the origin of the pandemic, suspicion, distrust of people around and social institutions, fear of distant threats and manifestations of misophobia.

For the iron discipline against the background of the pandemic, persons with high indicators on the scales of emotional $(r=0.279, \mathrm{p}<0.01)$ and behavioral coping $(\mathrm{r}=0.217, \mathrm{p}<0.01)$ spoke.

The carriers of esoteric thinking believe that epidemics are a weapon used by some people against others $(\mathrm{r}=0.371, \mathrm{p}<0.001)$, and do not agree that the emergence of new infectious diseases is a natural process of mutation that occurs in nature without the participation of people $(r=0.260, p<0.001)$ People with higher scores on the scales of categorical and personal-superstitious thinking turned out to have lower trust in the media and people around them.

\section{Pandemic Attitudes and Social Media Involvement}

The results of the correlation analysis show that among those who prefer social networks to official information (television, radio, print), there are statistically significantly more respondents characterized by low social and institutional trust. They have a more pronounced negative attitude towards the country's leadership, and they do not consider the efforts made by the authorities to contain the pandemic sufficient $(\mathrm{r}=-0.230$, $\mathrm{p}<0.001)$, do not believe in the possibilities of domestic medicine $(\mathrm{r}=-0.200, \mathrm{p}<0.001)$ and do not rely on themselves and their loved ones in a situation of illness $(\mathrm{r}=-0.190$, $\mathrm{p}<0.001)$.

In addition, among them there are more of those who not only do not trust official information about the epidemic situation $(\mathrm{r}=0.140, \mathrm{p}<0.001)$, but also do not trust their fellow citizens, attributing to them possible facts of concealing information about the disease due to fear of being quarantined $(r=0.130$, $\mathrm{p}<0.001$ ), and project their distrust of the official statistics on morbidity onto the majority of Russians $(\mathrm{r}=0.180, \mathrm{p}<0.001)$

\section{Conclusions}

The results of the study showed a spectrum of rather contradictory attitudes of the Russians' covid consciousness (fans / opponents of the "conspiracy theory"; responsible / irresponsible, covid-dissidents, covid-optimists, misophobes, anti-vaccinators). Individuals with constructive critical 
thinking and emotional coping proved to be more adaptive in assessing the epidemic situation. The older generation shows more confidence in the institutions of power and the people around them against the backdrop of the pandemic. Women have more anxiety and a tendency to misophobia than men. Among those citizens who derive information mainly from social networks, there were fewer people who trust both the authorities and their fellow citizens, as well as skepticism about medicine and vaccination.

\section{References}

Deyneka O.S., Maksimenko A.A. (2020). Psychological condition of society in a pandemic through the analysis of social networks: a review of foreign publications. Society. Environment. Development. No.2. pp. 28-39.

Enikolopov S.N. Kazmina, O.Yu., Vorontsova O.Yu., Medvedeva T.I., Boyko O.M. (2020). Dynamics of psychological reactions at the initial stage of the COVID-19 pandemic. Psychological and pedagogical research. Vol. 12. No.2. pp. 108-126.

Epstein S. (2001). CTI: Constructive Thinking Inventory: professional manual. Lutz, FL: Psychological Assessment Resources.

Fedosenko E.V. (2020). Life after Quarantine: The Psychology of Meanings and the COVID-19 Coronavirus. Psychological problems of meaning and acme. No.1. pp. 34-47.

Jia Z., Xu S., Zhang Z., Cheng Zh, Han H., Xu H., Wang M., Zhang H., Zhou Y., Zhou Zh. (2021). Association between mental health and community support in lockdown communities during the COVID-19 pandemic: Evidence from rural China. Journal of rural studies. pp. 87-97

Karadag E., Tosuntas S.B., Erzen E., Duru P., Bostan N., Sahin B. M., Culha I, Babadag B. (2015). Determinants of Phubbing, which is the Sum of Many Virtual Addictions: A Structural Equation Model. Journal of Behavioral Addiction. Jun; 4(2): 60-74. doi: 10.1556/2006.4.2015.005

Lebedev S.V., Enikolopov S.N. (2004). Adaptatsiya metodik issledovaniya posttravmaticheskikh stressovykh rasstroistv [Adaptation of methods for research post-traumatic stress disorders]. Psikhologicheskaya diagnostika = Psychological Diagnostic, No. 3, pp. 19-38. (In Russ.).

Liu H., Liu W., Yoganathan V., Osburg V.-S. (2021). COVID-19 information overload and generation Z's social media discontinuance intention during the pandemic lockdown, Technological Forecasting and Social Change. Vol. 166.

Mohamad S. M. (2020). Creative production of 'covid-19 social distancing' narratives on social media. Tijdschrift voor Economische en Sociale Geografie, Royal Dutch Geographical Society KNAG, vol. 111(3), pp. 347-359

Naeem M., Ozuem W. (2021) Customers' social interactions and panic buying behavior: insights from social media practices. Journal of Consumer Behavior DOI: 10.1002/cb.1925

Nestik T. A. (2020). Impact of the COVID-19 pandemic on society: socio-psychological analysis. Institute of Psychology of the Russian Academy of Sciences. Social and Economic Psychology. Vol. 5. No. 2 (18). pp. 47-82. 